\title{
O ENOTURISMO COMO PROMOTOR DA SUSTENTABILIDADE DA ATIVIDADE TURÍSTICA REGIONAL: O PROJETO DA “CASA DO VINHO DE VALPAÇOS"
}

\author{
Varico Pereira', Veronika Joukes ${ }^{2}$, Isabel Costa ${ }^{3}$, Xerardo Pereiro ${ }^{4}$ \\ 1 Instituto Superior da Maia - ISMAI; CEDTUR \\ 2, 3, 4 Universidade de Trás-os-Montes e Alto Douro; CETRAD
}

\begin{abstract}
Resumo: Este artigo resulta de um trabalho de investigação desenvolvido por quatro investigadores do Centro de Estudos Transdisciplinares para o Desenvolvimento (CETRAD), da Universidade de Trás-os-Montes e Alto Douro. O texto apresenta um resumo do projeto apresentado para implementação da Casa do Vinho de Valpaços, considerada como uma aposta no desenvolvimento do enoturismo no Norte Interior de Portugal. Trata-se de um espaço no qual se propõe contemplar diferentes valências - desenvolvimento económico, cultural, educativo, turístico - para assim ultrapassar largamente o tradicional conceito de museu, procurando constituir-se uma experiência variada e interativa para os seus visitantes.
\end{abstract}

Palavras-chave: Turismo, Enoturismo, Gastronomia e Vinhos, Alto Tâmega, Valpaços, Casa do Vinho, Educação.

Abstract: Wine tourism as a promoter of regional tourist activity sustainability: the "Wine House of Valpaços" project

This article stems from a research project developed by four researchers at the Center for Transdisciplinary Studies for Development (CETRAD), the University of Tras-os-Montes and Alto Douro. The paper presents a summary of the project submitted for implementation of the Wine House of Valpaços, regarded as a bet on the development of wine tourism in Northern Interior of Portugal. This is an area which proposes to contemplate different valences - economic, cultural, educational, tourism - in order to largely overcome the traditional concept of a museum, seeking to constitute a varied and interactive experience for your visitors.

Keywords: tourism, wine tourism, gastronomy and wines, Alto Tamega, Valpaços, House Wine, Education.

Resumen: El enoturismo como promotor de la sostenibilidad de la actividad turística regional: el proyecto de la "Casa del Vino" de Valpaços 
Este artículo es resultado de un trabajo de investigación desarrollado por cuatro investigadores del Centro de Estudios Transdisciplinarios para el Desarrollo (CETRAD), de la Universidad de Trás-os-Montes y Alto Duero. El texto presenta un resumen del proyecto presentado para la implementación de la Casa del Vino de Valpaços, considerada como una apuesta por el desarrollo del enoturismo en la zona interior norte de Portugal. Esta es un área que se propone contemplar diferentes valencias -desarrollo económico, cultural, educativo, turístico- para así superar ampliamente el concepto tradicional de museo, a la búsqueda de constituir una experiencia variada e interactiva para sus visitantes.

Palabras clave: turismo, enoturismo, gastronomía y vinos, Alto Támega, Valpaços, Casa del Vino, Educación.

\section{INTRODUÇÃO}

O presente texto é parte integrante da memória descritiva da candidatura à contrapartida anual da zona de jogo de Vidago-Pedras Salgadas, através da "Linha I do Programa de Intervenção do Turismo (PIT)", enquadra-se no âmbito da execução de obras declaradas de interesse para o turismo e visa a reconversão do antigo edifício da "Cooperativa dos Olivicultores de Valpaços", localizado no centro da cidade, para assim o transformar na Casa do Vinho que pretende ser um elemento catalisador que parte da sustentabilidade agrícola ambiental, da memória das populações locais, do turismo e da cultura científica na região de Trás-os-Montes, em geral, e do Alto Tâmega, em particular, para aumentar a visibilidade externa desta Região, a nível turístico, ambiental, cultural e científico.

O projeto "Casa do Vinho" deverá contar não só com verbas do PIT, mas também com o apoio do Fundo Europeu de Desenvolvimento Regional (FEDER), nomeadamente através de uma candidatura já entregue ao Programa Redes Urbanas para a Competitividade e a Inovação, formulada pela REDE ecoCITRAS, a Rede de Cidades Ecológicas e Inovadoras de Trás-os-Montes que abrange Bragança, Chaves, Macedo de Cavaleiros, Miranda do Douro, Mirandela e Valpaços.

No contexto do desenvolvimento turístico, o objetivo principal deste projeto é contribuir para a promoção e sustentabilidade da atividade turística regional e criar uma mais-valia para o desenvolvimento dos produtos turísticos Touring Cultural e Paisagístico, Turismo da Natureza e Gastronomia e Vinhos definido como estratégicos para o Norte de Portugal, pela política nacional e regional do Setor do Turismo (Fazenda, 2008; Portugal. MEID, 2011; Portugal. SET, 2006).

Embora o Município de Valpaços seja o promotor da beneficiação do edifício em causa e da reformulação do seu interior, atua em parceria com os outros membros da Associação dos Municípios do Alto Tâmega (AMAT), nomeadamente com os municípios de Vila Pouca de Aguiar, Ribeira de Pena, Montalegre, Boticas e Chaves, para reunir esforços no sentido de promover e dinamizar o aproveitamento de equipamentos diversificados, espalhados por esta região. 
Uma vez que não se trata de uma iniciativa isolada, acredita-se ser possível gerar um movimento turístico que enriquecerá, de forma despretensiosa, a região e o país, reforçando a oferta turística do Alto Tâmega. O projeto aqui em causa aproveita um edifício amplo e com localização central para a criação da Casa do Vinho em redor de 5 núcleos: um espaço museológico com espólio etnográfico, um espaço interpretativo, interativo, um espaço dedicado à relação do vinho e da sua produção com a ciência e tecnologia, uma adega típica e uma loja para venda de vinhos e outros produtos regionais, para assim apelar a um público-alvo de largo espetro.

Resumindo, o presente projeto tem como principal objetivo criar uma infraestrutura turística, complementar a outras já criadas ou a ser criadas na região do Alto Tâmega e Barroso, que ajude a dar visibilidade a práticas de produção agrícolas sustentáveis em Trás-os-Montes, envolvendo nomeadamente as componentes de:

- Museologia e etnografia: envolvendo uma componente museológica e etnográfica, com prioridade à demonstração das vantagens ecológicas e ambientais de alguns métodos de produção tradicionais;

- Ciência e tecnologia: envolvendo um espaço interativo, que relacione os produtos e meios produtivos tradicionais, nomeadamente do vinho, com a ciência e tecnologia (tipo Centro de Ciência Viva), vocacionado para a difusão da cultura científica e tecnológica através da observação e experimentação;

- Educação: as componentes anteriormente mencionadas contêm uma evidente vertente educativa, formal e não formal, dirigida não apenas aos públicos escolares mas também à população em geral;

- Promoção turística: envolvendo o Enoturismo, com a criação de loja, adega e produtos de merchandising destinados a aumentar a visibilidade externa da Região.

Realçamos, por fim, que os municípios do Alto Tâmega cada vez mais, e de forma consciente, apostam na criação de eventos e infraestruturas turísticas complementares, contrariam assim uma tendência verificada, por vezes, em Portugal: a não existência de práticas organizativas que apelem à capacidade de cooperação entre os diferentes atores chave no sentido da construção e implementação de uma estratégia partilhada de promoção da competitividade e de afirmação regional, em que se valorizem as complementaridades e os diferentes recursos existentes nas localidades envolvidas. Pelo contrário, e no caso presente, um trabalho em rede, a partilha de informação e a elaboração de propostas em conjunto criarão condições cada vez mais favoráveis à interiorização e ao aprofundamento da noção que em conjunto e com mútuo acordo, poderão ser executados, monitorizados, adaptados, avaliados e finalizados ainda muitos outros projetos.

\section{METODOLOGIA}

Como forma de justificar as opções tomadas para o desenvolvimento deste projeto, passa-se a descrever os métodos/técnicas de investigação e de trabalho utilizadas. 
Em primeiro lugar, foram analisados estudos e trabalhos editados pelos órgãos responsáveis pelo Turismo Português, a nível central e regional, para saber em que contexto geral este projeto específico do Alto Tâmega devia ser enquadrado. Realizou-se um encontro entre os seis municípios envolvidos e a equipa técnica responsável pela elaboração da candidatura na base deste projeto para estabelecer os objetivos gerais desta candidatura (e, também, os de outras) que tinha de se enquadrar nas ações desenvolvidas pelos vários municípios do Alto Tâmega para promover o desenvolvimento turístico. Prosseguiu-se com a análise da documentação fornecida pela AMAT e, em particular, pelo município de Valpaços ${ }^{1}$. Acrescentou-se um limitado exercício de benchmarking a nível internacional com o fim de sugerir ainda mais algumas oportunidades. Por último, mas não menos importante, a essência do que seguirá abaixo foi obtido, resulta de um feedback regular obtido, ao longo da fase da escrita, através da audição dos parceiros envolvidos.

\section{ENQUADRAMENTO TEÓRICO}

Este projeto enquadra-se em três eixos de reflexão teórica: a) os ecomuseus e os museus de território como instrumentos educativos e turísticos; b) os museus e rotas da alimentação; c) o enoturismo. A seguir apresentamos algumas notas teóricas fundamentais para a justificação da proposta que formam um elemento essencial deste projeto.

\subsection{ECOMUSEUS, MUSEUS, EDUCAÇÃO E TURISMO}

Logo que se pretende que a Casa do Vinho em Valpaços seja um ecomuseu que privilegia a formação e o contato com turistas, a abordagem de algumas noções teóricas nestas áreas se justifica.

Segundo o Observatório Mundial dos Ecomuseus (ver www.ecomusei.net/mondo), no mundo existem centenas de ecomuseus. Na Inglaterra, por exemplo, a resposta à crise económica industrial foi a criação de museus locais. Em 1980 chegou a haver 500, mais de 1/3 criados a partir de 1970 (Walsh, 1991). Em Setembro de 1971, Robert Poujade lança o conceito de "ecomuseu" na $9^{\text {a }}$ Conferência do ICOM, mas o criador da palavra foi Varine. O conceito está marcado pelas iniciativas a favor do desenvolvimento sustentado e em harmonia com o ambiente: tem uma orientação ecológica - ultrapassa a separação natureza/cultura; é um instrumento para a participação popular; promove o ordenamento do território, tal como uma tomada de consciência da população, visto o interesse primordial dado à comunidade.

Desde os anos 1990, os ecomuseus aumentam um pouco por todo lado e evoluíram em três sentidos diferentes (Roigé i Ventura, 2007):

1) Há pequenas instalações com poucos recursos que representam respostas à crise rural e industrial. Alguns destas mitificam o passado e distanciam-se da ideia

1 Foi-nos dado autorização de inserir algumas passagens desta documentação "interna" neste artigo. 
original dos ecomuseus, tendo uma menor preocupação com a investigação. Exemplos: casas rurais, moinhos, ferrarias, ...

2) Os vinculados ao desenvolvimento local e à integração comunitária. O risco é o cansaço das populações locais e dos visitantes, ao centrar-se mais num passado que fica cada vez mais longe.

Os parques etnológicos ou grandes instalações com atividades e instalações de recreação e restauração. Uma das mais recentes evoluções dos ecomuseus é o "economuseu”, um novo conceito com novos conteúdos (Roigé i Ventura, 2007). Inventadas em 1992 no Canadá por Cyril Simard, são instituições que articulam uma empresa artesanal com um museu e nas quais "o património ganha vida". Os economuseus combinam economia e cultura e representam uma associação entre a museologia e a empresa artesanal. $\mathrm{O}$ autofinanciamento é um elemento chave no seu funcionamento, sem colocar de lado a sua rentabilidade social e cultural. Os economuseus mercantilizam a ideia de museu e estão expostos a críticas, mas não deixam de motivar a reflexão sobre o papel do museu etnológico no desenvolvimento social e comunitário (http://www.economusees.com/sire_fr.cfm).

Hoje, a vertente educativa impregna praticamente todas as vertentes em que se sustentam os ecomuseus, pois é uma constante a sua preocupação com formar, informar e formar - numa palavra, educar - as populações, quer as autóctones, quer as visitantes. $\mathrm{O}$ compromisso com a educação é uma das tónicas dos ecomuseus e estende-se desde a educação das camadas mais jovens até à formação de técnicos e investigadores. Idealmente, os ecomuseus associam, assim, a informação com a formação em diversas vertentes e com a investigação.

Esta vertente educativa é visível também na aproximação que os ecomuseus fazem relativamente ao turismo. Desde sempre, as conceções de museu tendem a estar intimamente ligadas às artes e ao património cultural. Na sua relação com o turismo,os museus têm sido e são fundamentais na produção de cultura e património cultural.

Hoje, o museu é do público, entendido como cliente, mostra-se mais ao serviço da comunidade e é também dos vencidos e das vítimas, e não apenas dos vencedores. Do museu para combater "a taberna" passamos a um "museu-taberna", em função da necessidade de dinheiro. O museu utiliza, cada vez mais, o marketing para atrair turismo (Weil, 1999).

O turismo outorga novas funções ao museu e este concorre cada vez mais com outras indústrias de lazer. O museu é cada vez menos um simples conservatório e converte-se cada vez mais num meio de comunicação (Lumley, 1988:25; Hooper-Greenhill, 1998). Estes dois fatores levam a que o museu se preocupe cada vez mais com o acolhimento do visitante e com a relação com os seus públicos (Ver: www.visitorstudies.org), entre os quais se encontram os residentes locais e os turistas.

\subsection{MUSEUS E ROTAS TEMÁTICAS LIGADAS À ALIMENTAÇÃO}

Abordaremos em primeiro lugar os museus ligados à alimentação, como é o caso da futura Casa do Vinho a ser criada em Valpaços, para terminar com as rotas temáticas 
ligadas à alimentação, já que pelo menos uma, incluindo este projeto,poderia ser criada no Alto Tâmega, tão rico a nível gastronómico e de vinhos.

Os museus temáticos da alimentação centram-se nos alimentos como fio temático que orienta e guia a visita ou a experiência de visitação. É uma forma de atrair grandes públicos para o projeto museológico porque a alimentação é um tema transversal a toda a humanidade. Um bom exemplo é o Museu da Pesca de Palamós (Catalunya) (ver: www. museudelapesca.org). Este museu envolve a comunidade através do uso da memória e do património cultural marítimo através de atividades como passeios em barcos pesqueiros e conversas de taberna. Ao mesmo tempo, atrai turistas através de uma exposição sobre o peixe como alimento, fio condutor que diz alguma coisa aos visitantes e que os cativa. Outro bom exemplo de museus da alimentação é o museu do chocolate de Barcelona (ver: www.museudelaxocolata.com), promovido pelo grémio da pastelaria da capital da Catalunha.

Referimos ainda alguns museus dedicados, especificamente, ao vinho para ilustrar como cada um encontra a sua forma de se individualizar.

Em Paris situa-se, desde 1984, le Musée du Vin que hoje expõe mais de 2.200 objetos ligados ao vinho e à vinha (ver figura n. ${ }^{\circ} 1$ ). No entanto, ao longo do ano, o Museu do Vinho de Paris oferece também cursos de degustação e conferências, tal como organiza noites temáticas dedicadas, por exemplo, à descoberta de vinhos e alimentos dos países da União Europeia. Nas adegas abobadadas do século XV, situadas nas antigas caves da Abadia de Passy, o Restaurante Museu acolhe quem quiser desfrutar de uma refeição "menu" ou "à la carte". O Museu do Vinho de Paris também arrenda a profissionais e empresas (parte d)as suas instalações para seminários, festas, jantares ...; cria animações e workshops à medida, com ou sem álcool, explorando, em particular, os sentidos (especialmente olfato e paladar). Este espaço funciona igualmente como um centro de formação profissional (http://www.museeduvinparis.com).

Figura $n^{\circ} 1$ - Interior do Musée do vin (França)
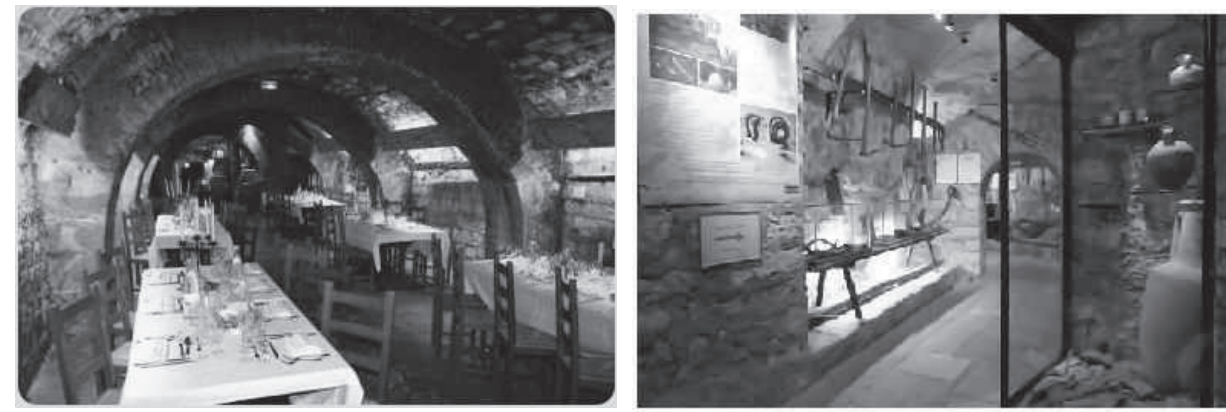

Fonte: http://www.museeduvinparis.com

São vinhas densas que dominam as encostas íngremes dos vales do rio Mosel. Trata-se da região vinhateira mais antiga da Alemanha. Em Bernkastel-Kues foi aberto em 2007 o Weinerlebniswelt - MultimedialesMoselweinMuseum (Mundo da experiência do 
vinho - Museu multimédia do vinho da região Mosel), um dos museus de multimédia mais avançadas da Alemanha, apostando, entre outros, em mais de 1.000 páginas de informações com muitos filmes e animações (ver figura $n^{\circ}{ }^{\circ}$ ). Quem termina a visita ao museu é convidado a uma degustação de vinho na loja de vinhos adjacente. Trata-se de um projeto que quer misturar a tradição (o produto) com a modernidade (informações sobre o produto) (http://www.moselweinmuseum.de).

Figura n. ${ }^{\circ} 2$ - Interior de Weinerlebniswelt(Alemanha)
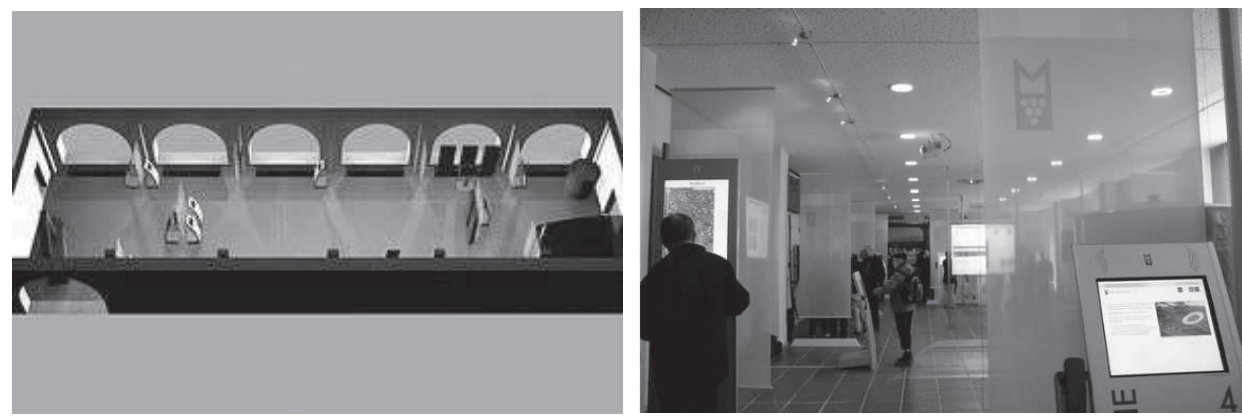

Fonte:

http://www.moselweinmuseum.de e http://www.flickr.com/photos/62971280@N07/5729481472.

Um museu alternativo que só pode ser visitado online, por enquanto, é WineandVineThings (Coisas da Vinha e do Vinho). O seu inventor, Jim McCormick, o descreve como um museu virtual de objetos antigos relacionados com a viticultura, enologia e o consumo de vinho (ver figura n. ${ }^{\circ} 3$ ). A coleção encontra-se em Petaluma (California) e inclui ferramentas, acessórios e químicos que permitem o plantio, crescimento, maturação e colheita das uvas para elas, eventualmente, chegar à mesa como vinho (http://www. wineandvinethings.com).

Figura n. ${ }^{\circ} 3$ - Página inicial de Wineandvinethings

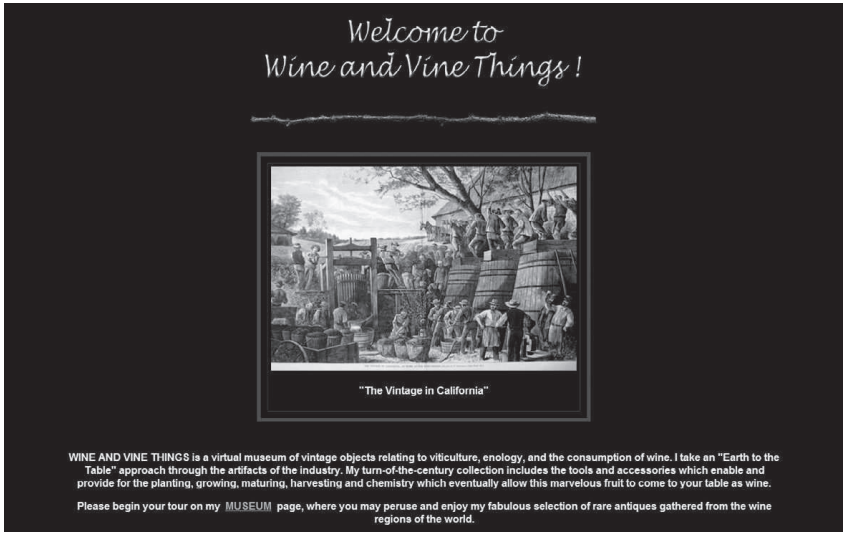

Fonte: http://www.wineandvinethings.com/index.html 
Os mais diversos museus dedicados à alimentação, mas também tabernas, restaurantes, artesãos, lojas com produtos regionais etc. podem ser inseridos em rotas.

Entre os tipos de rotas temáticas da alimentação destacamos:

- Rotas de produtos, como vinhos, queijo, chocolate, cerveja;

- Rotas de pratos cozinhados como fio condutor;

- Rotas étnico-gastronómicas com base em tradições culinárias particulares.

Em relação com as rotas temáticas da alimentação temos que refletir primeiro a mudança social da cultura turística que, de viajar com aprovisionamento do próprio viajante, passou a aprovisionar-se em restaurantes e espaços alimentares (lojas, centros comerciais, etc.). Do mesmo modo também mudou a noção da comida, pois converteu-se num prazer social e não apenas numa satisfação da necessidade básica de alimentar-se. Isto motivou o viajar para comer e viajar por comer, e também viajar através da comida por rotas temáticas. Neste sentido, a comida apresenta uma íntima relação com as migrações, a globalização e a localização. Estas três componentes inserem-se hoje nas rotas gastronómicas, tão potenciadas pelos média (TV, revistas e magazines, etc.) e também pela internet.

As rotas temáticas da comida e da bebida são favorecidas pela generalização do automóvel e apresentam-se muitas vezes associadas a festas gastronómicas. É neste contexto que se enquadram melhor as rotas do vinho, que já têm uma longa história nalguns países, como a Alemanha, onde as rotas do vinho fazem parte do turismo desde 1920 (Hall etal., 2004).

\subsection{O ENOTURISMO}

O hábito de levar consigo alimentos e bebidas como souvenirs ou recordações dos lugares visitados, tem como base o querer partilhar aromas e sabores com familiares e amigos, prolongando a experiência turística vivida e mostrando o capital cultural adquirido durante as férias (Richards, 2002: 15). Neste sentido o enoturismo é considerada um novo tipo de produto turístico:

El producto enoturismo consiste en la integración bajo el mismo concepto temático de los recursos y servicios turísticos de interés existentes y potenciales en una zona vitivinícola (proyecto VINTUR - RECEVIN).

Mas também, o enoturismo pode ser pensado como uma nova forma de fazer "turismo cultural". Também pode ser interpretado como uma leitura do território a partir do mundo do vinho e tendo este como fio condutor (ÁlvarezSolís, 2007: 60), centrando a sua oferta em:

- Elementos relacionados com o património natural: paisagens do vinho e caminhos.

- Elementos relacionados com o património cultural do vinho: museus, adegas, cursos de enologia, festas, eventos, povos, etc.

- Elementos relacionados com os serviços turísticos: alojamentos temáticos, centros de vinoterapia, lojas, enotecas... 
Nesta linha, podemos ter em atenção os seguintes exemplos espanhóis:

- Formação em degustação de e conhecimento sobre vinhos (exemplo: www. baconia.com);

- Rotas enoturísticas (exemplo: www.rutasdelvino.com);

- Aldeias do vinho com loja, hotel, restaurante, bar... (exemplo: Burgo de Papua em Ledesma; Mas de Ministrol, Anoia);

- Local de encontro onlinepara todas as pessoas, entidades e instituições que trabalham e/ou investem seu tempo livre numa combinação de jazz, literatura, enologia e gastronomia em Espanha (www.apoloybaco.com);

- Vinoterapia: ideia francesa do Château Smith HautLaffite, que abriu em Bordéus em 1999 o primeiro spa onde vinho (em vez de água) é utilizado no mundo "LesSources de Caudalie" e depois spas do género em, entre outros, Portugal, Turquia e Espanha;

- Museus do vinho: www.museosdelvino.es;

- Agências de viagens especializadas: www.enoviajes.com,www.viavinum.es, www.enodestino.com, www.paseosdelvino.com,www.evadium.com;

- Em Barcelona pode inscrever-se em vários WineTasting Tours;

Estes e outros exemplos mostram algumas tendências atuais da mobilização turística nacional e internacional a favor do projeto que a Autarquia de Valpaços quer realizar com a abertura da Casa do Vinho, que funcionará parcialmente como museu. Pretende tirar proveito da procura de produtos turísticos integrados e ancorados em propostas ligadas à conservação da natureza. Quer estimular o desenvolvimento de uma cultura territorial e ambientalmente mais sustentável. Explorará o maior interesse pelos patrimónios gastronómicos, enquanto representações simbólicas de uma região, e também enquanto experiências de contato intercultural enriquecedor. Por outras palavras, maximizará o interesse pela comida e a sua diversidade cultural.

\section{4. ÂMBITO TERRITORIAL DO PROJETO}

O projeto em causa é de caráter supramunicipal, apesar de estar localizado no concelho de Valpaços, a sua área de influência atinge todos os concelhos da Região do Alto Tâmega, que está integrada na sub-região estatística NUT III - Alto Trás-os-Montes da Região Norte de Portugal e compreende os municípios de Boticas, Chaves, Montalegre, Ribeira de Pena, Valpaços e Vila Pouca de Aguiar.

\subsection{CARACTERIZAÇÃO DA REGIÃO VITIVINÍCOLA EM CAUSA}

Segundo alguns autores, a cultura da vinha na região de Trás-os-Montes remonta ao tempo dos romanos, sendo que as condições edafo-climáticas da região favorecem a produção de vinhos de elevada qualidade. Contudo, só nos últimos anos a produção 
vitivinícola ganhou algum destaque. O reconhecimento surge fundamentalmente a partir de 1989, ano em que os vinhos produzidos em Chaves, no Planalto Mirandês e em Valpaços receberam a denominação Vinho de Qualidade Produzido em Região Determinada (VQPRD).

Figura n. ${ }^{\circ} 4$ - Mapa das regiões vitivinícolas de Portugal, destacando as de Trás-os-Montes
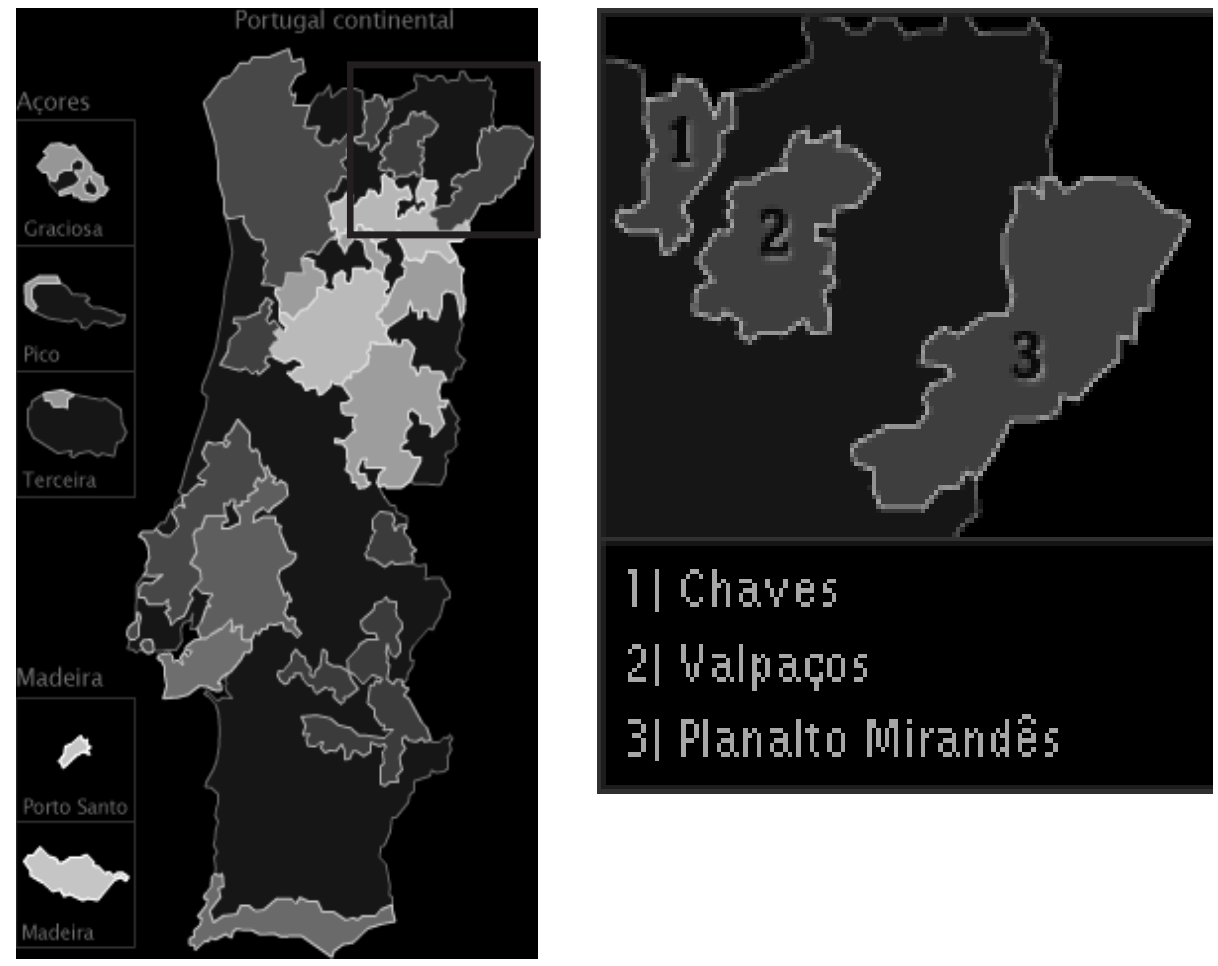

1) Chaves

2| Walpactos

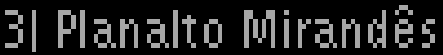

Fonte: http://www.infovini.com/classic/pagina.php?codPagina=10\&regiao=2

Mais recentemente, pela importância que têm vindo a assumir os vinhos provenientes desta grande região vitivinícola, quer do ponto de vista tecnológico, quer económico, foi reconhecida a Denominação de Origem Trás-os-Montes, bem como as suas sub-regiões "Chaves", "Planalto Mirandês" e "Valpaços". A sub-região Chaves abrange o concelho de Chaves e parte do concelho de Vila Pouca de Aguiar; a Sub-Região Planalto Mirandês abrange os concelhos de Miranda do Douro, Mogadouro e Vimioso e parte dos concelhos de Freixo de Espada à Cinta e Torre de Moncorvo; e a Sub-Região Valpaços abrange o concelho de Valpaços, a quase totalidade do concelho de Mirandela e parte dos concelhos de Macedo de Cavaleiros, Murça e Vinhais.

Constata-se, assim, que esta região vitivinícola abarca grande parte da região transmontana e, apesar da importância económica desta atividade na Região, o reconhecimento destes vinhos não acompanhou a rápida evolução qualitativa que sofreram nos últimos 
anos, a qual se ficou a dever, em grande parte, à modernização do setor e à reconversão das vinhas.

Este projeto surgiu não só de forma a contribuir para uma valorização cultural do vinho ligada ao território e às suas gentes, mas também para fortalecer o reconhecimento destes vinhos, projetando esta região não só como produtora de vinhos de qualidade, mas também para disseminar boas práticas ao nível da sustentabilidade ambiental.

Valpaços surge, neste território transmontano, como a escolha perfeita para a instalação da Casa do Vinho, uma vez que é um dos principais concelhos produtores da Região de Trás-os-Montes e é nesta cidade que se localizam as sedes de um conjunto de entidades de carácter regional relacionadas com a atividade vitivinícola, como a ACV, a Adega Cooperativa de Valpaços, a CVRT, Comissão Vitivinícola Regional de Trás-os-Montes, e a TrasVinis, Associação de Produtores e Engarrafadores de Trás-os-Montes, que tem como objetivo a promoção do vinho da região através, por exemplo, da criação de uma rota do vinho de Trás-os-Montes e da ajuda à promoção do turismo na Região.

Assume-se que a localização estratégica em Valpaços não restringe o potencial da Casa do Vinho à temática ou à Cidade e reconhece-se que, neste espaço, devem estar contempladas e inter-relacionadas as boas práticas agrícolas de Trás-os-Montes e a incorporação crescente de um conceito eco que se reflete na História e Antropologia (espaço museológico), na Ciência e Tecnologia (espaço interativo e dedicado à observação e experimentação) e na Cultura (adega e loja). A Casa do Vinho deverá funcionar numa lógica de "museu de território" e "museu social", em contraponto com os modelos mais tradicionais de museu. Assim, a Casa do Vinho deverá articular-se com outros núcleos museológicos na região, ligados ao vinho, à vinha e, de um modo geral, a práticas agrícolas sustentáveis, potenciando, deste modo, iniciativas diversas e estimulando a itinerância de exposições e outras ações culturais. Será importante,por isso,envolver no projeto as comunidades e as instituições da região, na medida em que vão ser os seus primeiros beneficiários.

\subsection{AÇÕES A DESENVOLVER}

A Casa do Vinho deverá ser um espaço polifuncional que se pretende venha a contribuir simultaneamente para a preservação da memória social comunitária e para a dinamização de um espírito científico e tecnológico nos jovens de Valpaços e de toda a região de Trás-os-Montes. O espaço que se propõe contempla diferentes valências, procurando constituir-se como uma experiência variada e interativa para os seus visitantes. Utilizando o tema do vinho, refletindo a importância de métodos agrícolas de produção sustentável, e destacando assim o seu potencial educativo,o espaço deverá apresentar um carácter científico, lúdico e didático, incluindo diferentes valências, tais como:

- Valência museológica com espólio antropológico, de apelo à memória das populações locais, podendo albergar exposições permanentes e temporárias; 
- Valência interpretativa interativa, com apresentações sobre a capacidade de uma produção contínua com base em recursos gerados pela própria produção (referência ao conceito de autossuficiência) exemplificando o processo produtivo do vinho, destacando a sua importância ecológica, social e económica, diferenciando os tipos de vinho, a sua utilização e reforçando a sua relação com a gastronomia regional; além do mais, serão tidas em atenção as formas e significados da distribuição e os consumos do vinho em contextos locais, regionais e internacionais;

- Valência da produção do vinho combinado com a valência da relação do mesmo com a ciência e tecnologia, promotora de boas práticas ambientais, vocacionado para a difusão da cultura científica e tecnológica através da observação e experimentação (de sabores, cores, saberes, formas...);

- Valência da mediação entre locais e visitantes e valência da promoção dos produtos regionais, especialmente osvinhos, concentrados na adegatípica com provas comentadas de vinhos da Região e na loja para venda de vinhos e outros produtos regionais

É de realçar que, no âmbito do espaço e das atividades dedicadas à "relação do vinho com a ciência e tecnologia", se procura incorporar o contributo de especialistas relacionados com instituições de I\&D e de ensino superior da região, tal como com o Instituto da Vinha e do Vinho, no sentido de promover a conceção do espaço de modo a poder vir a candidatar-se à rede de "Centros de Ciência Viva". Estes centros são espaços interativos de divulgação científica e tecnológica distribuídos pelo território nacional, que funcionam como plataformas de desenvolvimento regional (ambiental, científico, cultural e económico) através da dinamização dos atores regionais mais ativos nestas áreas. Ao mesmo tempo, representam a moderna museologia da ciência e são espaços dinâmicos de conhecimento e lazer, onde se estimula a curiosidade científica e o desejo de aprender.

O projeto da Casa do Vinho será realizado pela Câmara Municipal de Valpaços, envolvendoainda, e para além do Centro de Excelência do Vinho e da Vinha (CEVV), um conjunto de atores locais e regionais com os quais já existem protocolos de colaboração, com destaque para a Comissão Vitivinícola Regional de Trás-os-Montes (CVRT), a Associação de Produtores e Engarrafadores de Trás-os-Montes (TrasVinis) e a Associação de Vitivinicultores de Trás-os-Montes (AVITRA). O envolvimento destes parceiros terá como objetivos primordiais a realização de atividades interativas com o público e a disponibilização de produtos para venda na adega típica.

O projeto da casa do Vinho pressupõe um investimento significativo, cujo montante global está estimado para construção do edifício da Casa do Vinho, incluindo mobiliário, equipamento e arranjos exteriores. O funcionamento da Casa do Vinho será, numa primeira fase, assegurado por 3 técnicos. 


\section{A RELEVÂNCIA DO PROJETO PARA O TURISMO}

Como já foi dito, a finalidade principal deste projetoé o enriquecimento e a diversificação da oferta turística e cultural em Valpaços e no Alto Tâmega, através da reconversão do edifício da "Cooperativa dos Olivicultores de Valpaços" em Casa do Vinho. Este conceito contém, em si, uma ideia de museu que vale a pena enquadrar.

Uma vez que os museus costumam ser visitados não só pelos residentes do próprio local ou da própria região, mas também por visitantes mais longínquos e com certeza também por turistas nacionais e internacionais, admitimos como plausível que os turistas serão quem mais visitarão a futura Casa do Vinho.

Neste sentido, deve ser sublinhado que o Alto Tâmega apresenta um conjunto de potencialidades que constituem já fontes de atração turística (e não só a nível de museus), mas que o podem ser ainda mais, à medida que a região vai conseguindo apostar no desenvolvimento local. Considerando o perfil dos turistas que visitam a região, pretende-se captar (i) turistas internacionais, nomeadamente do mercado espanhol/galego e (ii) ao nível do mercado nacional, embora se pretenda atrair turistas oriundos de todas as regiões do país, espera-se sobretudo um aumento significativo do número de turistas da região norte, principalmente vindos da região do Minho e grande Porto. Mas também se visa atrair turistas no que se pode denominar de "mercado de saudade", nomeadamente do Brasil e dos Estados Unidos da América.

Destacam-se, em seguida, alguns aspetos que, se devidamente enquadrados, podem contribuir para fomentar a multi-oferta desta região, do ponto de vista da relevância turística.

Resumindo, dando uma nova vida ao antigo edifício da Cooperativa de Viticultores de Valpaços recuperam-se elementos do património histórico e cultural, valoriza-se o território, oferecendo-lhe uma maior projeção e visibilidade, promove-se a melhoriadas condições de vida das populações locais e aumenta-se as expetativas de investimento privado na vertente do alojamento e da restauração. Cabe ainda destacar que a integração da população no projeto de desenvolvimento é essencial.

\subsection{CONTRIBUTO EFETIVO PARA A VISITA DOS TURISTAS}

Tornando esta região mais atrativa, este projeto permitirá, por um lado, oferecer mais um motivo para visitar a mesma, por outro lado possibilitará uma melhor prática turística e uma melhor satisfação da expetativa dos visitantes, porque contribuirá decisivamente para conhecer a cultura do vinho da região através de infraestruturas culturais e experiências de contato que não se reduzem ao simples alojamento. Falando em alojamento, o Alto Tâmega pode-se orgulhar num número crescente de camas (hotéis, unidades de turismo em espaço rural, parque de campismo). Tendo uma oferta hoteleira variada, os mais diversos produtos turísticos apelativos e alguma animação turística, este projeto pode contribuir para a satisfação do visitante, cada vez mais interessado no turismo alimentar (Fagliari, 2005; INE, 2011). 
Em consequência da constante melhoria do nível de vida, das alterações demográficas e de fatores como a globalização e novos meios de comunicação, e sensivelmente na última década, surge um novo tipo de turista que tem preferência pelo imaginado como mais natural, rural, calmo e tranquilo. Este novo turista tem como principal motivação a vivência de emoções e sensações cada vez mais personalizadas e diferenciadas, proporcionadas pelas características e pela excelência dos produtos, bem como por experiências novas e enriquecedoras. Não sendo exceção, os turistas culturais, por exemplo, procuram cada vez mais experiências que os ponham em contato com as culturas locais e que lhes permitem desenvolver o seu próprio potencial pessoal.

Espera-se que a Casa do Vinho de Valpaços, por via das suas vertentes turística e museológica e educativa, contribua para a valorização do local, aumentando assim as expetativas de aparecerem investidores privados na vertente do alojamento, da restauração e da animação turística. É precisamente isso que se pretende: criar um equipamento turístico com capacidade de induzir dinâmicas de visitação à cidade com externalidades positivas nas demais atividades turísticas já existentes no concelho e na região, em especial na hotelaria, na restauração e no comércio em geral.

Com certeza os turistas estrangeiros no norte de Portugal estão muito habituados a ver um tipo de museu do vinho: as caves do vinho do porto ao longo do Douro. Nas regiões vinhateiras no interior do país, porém, há muito menos oferta apesar da importância deste produto agrícola. No entanto, o visitante/turista não quer apenas apreciar a riqueza paisagista destes locais, mas sim, conhecê-los e ter experiências diferenciadas. Pode fazer isso com uma visita a um museu do vinho. Os projetistas da Casa de Vinho de Valpaços inspiram-se numa série de museus que representam a produção de uma região, e não de uma única empresa, como por exemplo o Museu do Vinho de Redondo (Alentejo) (http://www.cm-redondo.pt/pt/conteudos/actividade $\% 20$ municipal/tempos $\% 201$ vres\%20e\%20desporto/Museu\%20Regional\%20do\%20Vinho.htm),o Museu do Vinho do Oeste localizado em Alenquer (http://www.cm-alenquer.pt/CustomPages/ShowPage. aspx?pageid=df2d987c-cb5e-4e26-b7cc-5fd2f1144150) ou o Museu do Vinho Bairrada em Anadia (http://www.lusowine.com/displayarticle1449.html).

O que se pretende realizar em Valpaços não é, atualmente, a única iniciativa neste sentido. Referimos neste contexto que o futuro Museu do Vinho do Dão funcionará numa construção, em tempos ligada à vida agrícola de depósito de alfaias e animais existente na Vila de Santar, Concelho de Nelas. O edifício atual está abandonado e é composto por um corpo principal todo em pedra aparelhada e anexa um telheiro em avançado estado de degradação. Uma breve leitura do plano arquitetural do Museu do Vinho do Dão revela duas zonas de exposição, uma permanente e outra temporária, um bar e um restaurante de apoio ao funcionamento do Museu e ainda uma zona promocional dos produtos da Região do Dão (http://www.cm-nelas.pt/portal/page?_pageid=604,16610906\&_dad=portal\&_ schema=PORTAL).

Através da implementação da Casa do Vinho de Valpaços, disponibiliza-se um produto ainda inexistente na região do Alto Tâmega, na medida em que possibilita conhecer a história, memória e cultura desta sub-região vinícola. Por outro lado, pode-se apresentar 
esta oportunidade como fazendo parte de um produto compósito que combina o Touring Cultural e Paisagístico, o Turismo de Natureza e a Gastronomia, pois insere-se numa região com vocação para este tipo de produtos, com um vasto leque de atrações locais únicas, permitindo um conhecimento mais aprofundado e diferenciado das gentes e do território do Alto Tâmega.

O Alto Tâmega, em particular o concelho de Valpaços, ganha com este projeto um atrativo único capaz de dinamizar uma nova procura turística para a região. Tornando-a assim mais apetecível e capaz de satisfazer, de forma simultaneamente tradicional e inovadora, as expetativas dos visitantes/turistas que encontrarão neste território uma oferta turística, desenvolvida de forma articulada pelas várias entidades com intervenção no turismo, de forma a preparar uma oferta turística, estruturada, coerente e articulada, capaz de satisfazer as necessidades, motivações e expetativas do turista, surpreendendo-o, até.

Atualmente, a visita turística ao Alto Tâmega é marcada sobretudo pelo touring cultural e paisagístico e pela saúde e bem-estar. No entanto, o Alto Tâmega possui muito mais valências, tornando-se necessário colmatar a alguma carência de "massa crítica" turística, de modo a contribuir para o aumento da permanência média e a diversificação de fatores de atracão turística.

O projeto vemcriar uma infraestrutura que forneça motivos para ficar mais tempo no Alto Tâmega. Esta nova infraestrutura reforçará os programas de visita de alguns operadores, para além de complementar os serviços disponibilizados pelas unidades de alojamento, empresas de animação e restauração. Deste modo, cria-se uma complementaridade entre os agentes a atuar no território, possibilitando o usufruto, por parte de quem visita o Alto Tâmega, de uma oferta integrada e coordenada que permite o conhecimento aprofundado do Alto Tâmega em todas as suas vertentes, bem como o usufruto integrado dos serviços disponibilizados. Conforme o exemplo da Rota da Vinha e do Vinho do Oeste, promovido entre outros pelo Museu do Vinho do Oeste, a Casa do Vinho pode a médio prazo vir a conceber, ainda, uma ou várias rotas ligadas aos vinhos da região.

Para garantir um aumento dos fluxos turísticos não só para esta nova casa-museu, mas também para todo a região do Alto Tâmega estão a ser estabelecidas parcerias de colaboração com diferentes entidades de âmbito local, regional e nacional, de forma a unir sinergias e criar uma rede de oferta concertada que permita consolidar produtos turísticos de qualidade. Entre as entidades que apoiam e pretendem colaborar com a Casa do Vinho encontram-se cooperativas de turismo e de agricultura, hotéis, casas de turismo rural, restaurantes, empresas de animação turística, confrarias, associações de produtores, tal como associações locais e regionais.

Importa, por fim, reforçar o carácter complementar do projeto apresentado, permitindo a sua articulação com outros projetos já existentes e a criar, bem como a sua contribuição para a atração de mais fluxos turísticos para o território. Reforça também o posicionamento do Alto Tâmega como destino de Touring Cultural e Paisagístico e Gastronomia e Vinhos.

O espaço que se propõe contempla diferentes valências e ultrapassa largamente o tradicional conceito de museu, procurando constituir-se como uma experiência variada e interativa para os seus visitantes. 
Pretende-se que a Casa do Vinho seja um elemento catalisador em paralelo da sustentabilidade ambiental, da memória das populações locais, do turismo e da cultura científica na região de Trás-os-Montes, aumentando a visibilidade externa desta Região, a nível turístico, ambiental, cultural e científico.

Não obstante a disseminação, direta ou indireta, sustentada pelas ações de divulgação e comunicação previstos ou pela transferência emergente das visitas aos espaços e subsequente divulgação na comunidade, o Projeto da Casa do Vinho assenta num produto diferenciado, onde a inovação e a qualidade desempenham um papel fundamental.

\section{CONSIDERAÇÕES FINAIS}

O concelho de Valpaços, inserido na região do Alto Tâmega, é detentor de um património valioso, tal como toda a região, relevando-se, ainda, a proximidade territorial com Espanha. A aposta no turismo é, sem dúvida, um dos fatores que mais pode contribuir para um desenvolvimento económico sustentável, constituindo um importante fator dinamizador das zonas rurais, capaz de gerar mais-valias para o território, quer de forma direta, através das receitas provenientes deste sector, quer de forma indireta, como resultado do aumento do empreendedorismo da população local.

Tratando-se de uma região com características naturais e tradições riquíssimas, torna-se fundamental preservar e difundir o património natural, social e cultural e ao mesmo tempo criar e dinamizar equipamentos de apoio onde se possa mostrar todo o potencial da região. Importa, deste modo, apostar na vertente turística, através da modernização dos equipamentos, com melhorias que garantem a acessibilidade e funcionalidade dos espaços.

Assim, prevê-se que os impactos gerados por este projeto sejam muito positivos, a vários níveis. O presente projeto, além de funcionar como catalisador na captação de visitantes, constitui uma mais-valia para o território, na medida em que a sua promoção terá igualmente um efeito junto da população, contribuindo para o desenvolvimento de uma dinâmica local de consciencialização, identidade e defesa do património do concelho. Ao aliar ruralidade e tecnologia, cujos conceitos parecem antagónicos, será ainda mais marcante o impacto que a promoção irá ter sobre os visitantes.

Desde logo, e dada a proximidade geográfica, pretende-se captar turistas do mercado espanhol, com especial destaque para o mercado de proximidade, nomeadamente das regiões da Galiza e de Castela e Leão. Este projeto permitirá reforçar e enriquecer a oferta turística e as rotas de interesse turístico que atravessam a região transfronteiriça.

Com este equipamento pretende-se, também, dar um novo impulso à economia local, através da dinamização de alguns sectores, nomeadamente dos estabelecimentos integrados na Rede de Tabernas do Alto Tâmega e das Cozinhas de Venda Direta, constituindo um incentivo à produção de produtos locais de qualidade, servindo igualmente como alavanca para o surgimento de novas atividades ligadas ao sector turístico (alojamento, restauração e outros serviços). Desta forma, prevê-se a obtençãode impactos económicos 
e socioculturais positivos, pois criará novos empregos diretos e indiretos, contribuindo para a melhoria da qualidade de vida das populações locais.

Tirando partido das grandes potencialidades, quer naturais, quer construídas, o concelho pode oferecer um turismo de excelente qualidade nas suas diversas vertentes - Turismo de Natureza, Turismo de Saúde e Bem-Estar, Turismo em Espaço Rural, Ecoturismo, entre outros, sendo várias e diversificadas as rotas temáticas que atravessam a região, nomeadamente, a Rota do Alto Tâmega, a Rota das Vias Augustas, a Rota da Castanha, o Percurso da Judia, o Percurso Dourado da Padrela e a Rota do Vinho, em criação, onde a Casa do Vinho virá a desempenhar um importante papel.

São várias as dinâmicas que se têm criado à volta deste projeto, unindo-se sinergias de diferentes sectores, desde a gastronomia / restauração, às atividades hoteleiras, agentes turísticos e animação turística, locais, regionais e nacionais, que levaram diversas entidades a subscrever as declarações de apoio ao projeto e vontade de cooperar com a Casa do Vinho para fortalecer, especialmente, o produto turístico estratégico TouringCultural e Paisagístico e servir de oferta complementar, em termos de ocupação de tempos livres, a outros produtos turísticos, tais como Turismo de Natureza, Saúde e Bem-estar, Gastronomia e Vinhos, ajudando a consolidar a posição da região do Porto e Norte de Portugal como um destino turístico diferenciado e de qualidade, fortalecendo a posição do destino Portugal.

A posição geoestratégica deste equipamento, a forma inovadora e original como aborda o território, integrando a cultura, as atividades e os produtos tradicionais da região na oferta museológica e não só, vai permitir não apenas enriquecer a experiência dos turistas, com uma oferta inovadora e diferenciada e, também, preservar e potenciar o património histórico-cultural e captar novos fluxos turísticos para a região, incentivando a permanência dos turistas no território e melhorando a circulação intrarregional, entre os vários concelhos da AMAT, uma vez que este equipamento se transformará num museu complementar aos demais que se encontram espalhados pela região do Alto Tâmega e Barroso.

Deve ser ressalvado que este museu será divulgado e apoiado através de outra rede bem estruturada de que o Município de Valpaços faz parte: a rede ecoCITRAS que engloba as cidades ecológicas e inovadoras Bragança, Chaves, Macedo de Cavaleiros, Miranda do Douro, Mirandela e Valpaços. Redeesta que promove o turismo como área de ação ao lado da agro-indústria, da energia e da construção. Reiteramos neste contexto que o projeto apresentado se define implicitamente como um produto turístico sustentável.

Resumimos que se trata de um projeto realista e relativamente modesto através do qual

- um equipamento existente será melhorado e inovado, abraçando a realidade vinhateira com ferramentas multimédia;

- sinergias com diversas interlocutores (outros museus/restaurantes/adegas/lojas de produtos locais/entidades turísticas da região) serão reforçadas;

- se concretiza mais um passo no caminho do município de Valpaços em valorizar os seus produtos locais; 
- o Alto Tâmega se projeta como uma região seguidora de práticas agrícolas sustentáveis e como produtora de produtos de qualidade (entre outros o vinho);

- se enriquece os produtos turísticos estratégicos (i) Touring Cultural e Paisagístico e (ii) Turismo gastronómico e de vinhos, definidos pela política nacional e regional do setor do turismo, para a região Norte de Portugal;

- se promove o enriquecimento educativo e culturalde vários segmentos populacionais

- se possibilita dar relevância a Valpaços em roteiros regionais, intrarregionais, e internacionais;

- se percebe a existência de um trabalho em rede para combater o êxodo rural, e de uma aposta na criação de valor através do turismo;

- se percebe que o município de Valpaços ganha escala por já não disputar as mesmas funções e equipamentos com outros municípios próximos, mas sim, manter o diálogo aberto e organizar-se, valorizando as diferenças e cooperando para reforçar sinergias e complementaridades;

Este projeto é, pois, mais uma iniciativa desenvolvida no sentido de garantir que os agentes a atuar no território se complementam, possibilitando o usufruto, por parte de quem visita o Alto Tâmega, de uma oferta integrada e coordenada que permite reforçar o bem-estar material e cultural das populações, aumentando o conhecimento aprofundado da região em todas as suas vertentes, bem como o usufruto integrado dos serviços disponibilizados.

\section{BIBLIOGRAFIA}

Álvarez Solis, C. (2007): Enoturismo, una nueva forma de turismo emergente. Ábaco, $56-68$

Fagliari, G. S. (2005): Turismo e Alimentação-Análises Introdutórias.Editora Roca.

Fazenda, N. (2008): Plano Regional de Ordenamento do Território do Norte - PROT-NORTE. Temática turismo. O turismo na Região do Norte de Portugal. Porto, CCDR-N e Ministério do Ambiente, do Ordenamento do Território e do Desenvolvimento Regional.

Hall, C. M. et al. (Org.) (2004): Wine tourism around the world: development, management andmarkets. Oxford: Elsevier.

Hooper-Greenhill, E. (1998): Los museos y sus visitantes. Gijón: Trea.

INE, I. P. (2011): Anuário estatístico da Região Norte 2010. Lisboa: INE.

Lumley, L. (ed.) (1988): The Museum Time-Machine. London: Routledge.

Mapa das regiões vitivinícolas de Portugal. Consultado em Outubro de 2012, de http:// www.infovini.com/classic/pagina.php?codPagina $=10 \&$ regiao $=2$

Moselweinmuseum. Consultado em Novembro de 2011, de http://www.moselweinmuseum.de/ 
Musée du vin de Paris. Consultado em Novembro de 2011, de http://www.museeduvinparis.com.

Museu de la Pesca. Consultado em Novembro de 2011, de http://www.museudelapesca.org.

Museu do Vinho Bairrada. Consultado em Novembro de 2011, de http:/www.lusowine. com/displayarticle1449.html.

Museu do Vinho de Redondo. Consultado em Novembro de 2011, de http://www.cm-redondo.pt/pt/conteudos/actividade\%20municipal/tempos $\% 201$ ivres $\% 20 \mathrm{e} \% 20$ desporto/Museu\%20Regional\%20do\%20Vinho.htm.

Museu do Vinho do Dão. Consultado em Novembro de 2011, de http://www.cm-nelas.pt/ portal/page?_pageid=604,16610906\&_dad=portal\&_schema=PORTAL.

Museu do Vinho do Oeste. Consultado em Novembro de 2011, de http://www.cm-alenquer.pt/CustomPages/ShowPage.aspx?pageid=df2d987c-cb5e-4e26-b7cc$5 \mathrm{fd} 2 \mathrm{f} 1144150$.

Museus delVino. Consultado em Novembro de 2011, de http://www.museosdelvino.es.

Observatório Mundial dos Ecomuseus. Consultado em Novembro de 2011, de http:// www.ecomusei.net/mondo.

Patrimonios culturales y museos. Más allá de la historia y del arte. Donostia: EuskalErr icoUniversitatea(Universidade do País Basco).

Portugal. MEID. (2011): Plano Estratégico Nacional do Turismo. Propostas para revisão no horizonte 2015 - Versão 2.0. Lisboa: MEID e Turismo de Portugal.

Portugal. SET. (2006): PENT - Plano Estratégico Nacional do Turismo. 2006-2015. Lisboa: SET.

RéseauÉconomusée. Consultado em Novembro de 2011, de http://www.economusees. com/sire_fr.cfm.

Richards, G. (2002): "The scope and significance of cultural tourism", in Richards, G. (ed.) Cultural Tourism in Europe, Wallingford, CAB International, pp. 19-45.

Richards, G. (ed.) (2002): Cultural Tourism in Europe. Oxon: CAB International.

Roigé i Ventura, X. (2007): “La reinvención del museo etnológico”, in Arrieta Urtizberea, I. (ed.):

Turismo de Portugal, IP (2007): PENT, Plano Estratégico Nacional de Turismo. Lisboa: Ministério da Economia e da Inovação.

Turismo do Porto e Norte de Portugal, ER (2010): Plano de atividades e orçamento 2010. Viana do Castelo: [S.n.].

VisitorStudiesAssociation. Consultado em Novembro de 2011, de http://www.visitorstudies.org.

Walsh, K. (1991): The Representation of The Past: Museums and Heritage in the Posmodern World. London: Routledge.

Weil, S. E. (1999): "El museo y el público". Revista de Museología, 16: 17-25.

Weinerlebniswelt - MultimedialesMoselweinMuseum. Consultado em Novembro de 2011, dehttp://www.moselweinmuseum.de.

Wineandvinethings. Consultado em Novembro de 2011, de http://www.wineandvinethings.com. 